\title{
O CONTAR DA COR: A RESISTÊNCIA ATRAVÉS DA HISTÓRIA, DAS LINGUAGENS E DAS CULTURAS DOS NEGROS AFRICANOS $^{1}$
}

\author{
Anselmo Peres Alós ${ }^{2}$ \\ Felipe Freitag ${ }^{3}$
}

RESUMO: Um delineamento dos sinais de identidade nacional e de crítica social na "arte de tematização do urbano, ou citadino" aparece como o tema deste artigo, na medida em que se configura como uma linguagem de representação das culturas africanas. Foram selecionados para análise da composição, duas obras do artista plástico angolano Lino Damião, que de alguma forma parecem horizontalizarem-se sob símbolos específicos da cultura urbana em alguns países africanos, mais especificamente de Angola.

PALAVRAS-CHAVE: Linguagem não-verbal; Culturas africanas negras; Identidade nacional; Crítica social; Inclusão social.

RESUMEM: Un esquema provisional de los signos de identidad nacional y la crítica social en el "arte de la tematización de lo urbano o la ciudad" aparece como el lema de este artículo, en el que se configura como un lenguaje que representa a las culturas africanas. Se seleccionaron para el análisis de la composición, dos obras de artista plástico angoleño, Lino Damião, que de alguna manera parece horizontalizarem bajo una simbología específica de la cultura urbana en algunos países africanos, con la preponderancia Angola.

PALAVRAS-CLAVE: Lenguaje no verbal; Las culturas africanas negras; Identidad nacional;

Crítica social; La inclusión social.

\section{Introdução}

\footnotetext{
${ }^{1}$ Artigo elaborado para a disciplina de Cultura Lusófona do curso de Letras Português (Licenciatura) da Universidade Federal de Santa Maria.

${ }^{2}$ Autor. Doutor em Literatura Comparada pela UFRGS. Professor do Departamento de Letras Vernáculas da UFSM. Orientador do projeto de pesquisa Ressonâncias e dissonâncias no romance lusófono contemporâneo: o imaginário pós-colonial e a (des)construção da identidade nacional.

${ }^{3}$ Autor. Acadêmico do curso de Letras Português (Licenciatura)-UFSM e orientando no projeto de pesquisa Ressonâncias e dissonâncias no romance lusófono contemporâneo: o imaginário pós-colonial e a (des)construção da identidade nacional, coordenado pelo Prof. Dr. Anselmo Peres Alós.
} 
Lino Damião nasceu em Luanda (Angola), em fevereiro de 1977; trabalha, sobretudo com pintura e gravura, através de abstração e de geometrização. Frequentou o curso de desenho no "Ex-Barracao" e o curso de pintura na "UNAP", bem como o atelier do mestre Victor Texeira. É membro fundador da "Cooperativa Pró-Memória dos Nacionalistas" e membro da "União Nacional dos Artistas Plásticos".

Participou em diversas exposições, dentre as quais, a primeira Bienal de jovens criadores da "CPLP (Comunidade dos Países de Língua Portuguesa)"4 em 1999. O artista em questão tenciona, majoritariamente, em suas obras, a cultura urbana, o cotidiano, os preconceitos e a religiosidade.

Levando-se em consideração uma perspectiva de identidade nacional como um construto imagético coletivo, poder-se-á evidenciar certos modos de composição identitária da sociedade urbana de Angola, a partir de mecanismos de interpretação temática e não no que concerne aos elementos teóricos da arte pictórica.

Um mapeamento de elementos conceituais da identidade nacional angolana e da crítica social nas obras de Lino Damião parte do pressuposto de que os espaços da arte possibilitam interlocuções do individual representado (pelo artista) pelo coletivo representável (pela obra), ou seja, o público estabelece um processo de negociação de sentidos na e pela obra.

Entende-se aqui o conceito de "angolanidade" como traços essenciais, ou códigos de referência de culturas que compõem a sociedade angolana, sendo assim, não um conceito estanque, mas uma formulação encadeada por multiplicidade de aspectos representativos de uma ordem pré-existente da diversidade dos sentidos de identidade.

Portanto, a "angolanidade" é muito mais uma construção do ser e do estar de uma Nação do que um atributo coletivo identificável e reconhecível. O que se analisará nas obras do artista plástico em questão será a materialização artística das várias modalidades possíveis da experiência angolana em seu espaço urbano, na busca por uma identidade social positiva em contraponto a identidades sociais negativadas ao longo da história pelos colonizadores.

\footnotetext{
4“A Comunidade dos Países de Língua Portuguesa - CPLP é o foro multilateral privilegiado para o aprofundamento da amizade mútua e da cooperação entre os seus membros. Criada em 17 de Julho de 1996, a CPLP goza de personalidade jurídica e é dotada de autonomia financeira." Disponível em: <http://www.cplp.org/id-46.aspx>. Acesso em: 13 jul. 2013.
} 
As obras de Lino Damião parecem realizar um esforço imaginativo (mediado pela criação subjetiva da obra de arte) na criação de instrumentos de discursos do urbano em Angola através de esferas do cotidiano, bem como de discursos de denúncia e crítica social na legitimação de aspectos sociais e culturais da "gente" de seu país.

\section{A ANÁLISE E SEUS DESDOBRAMENTOS INTERPRETATIVOS}

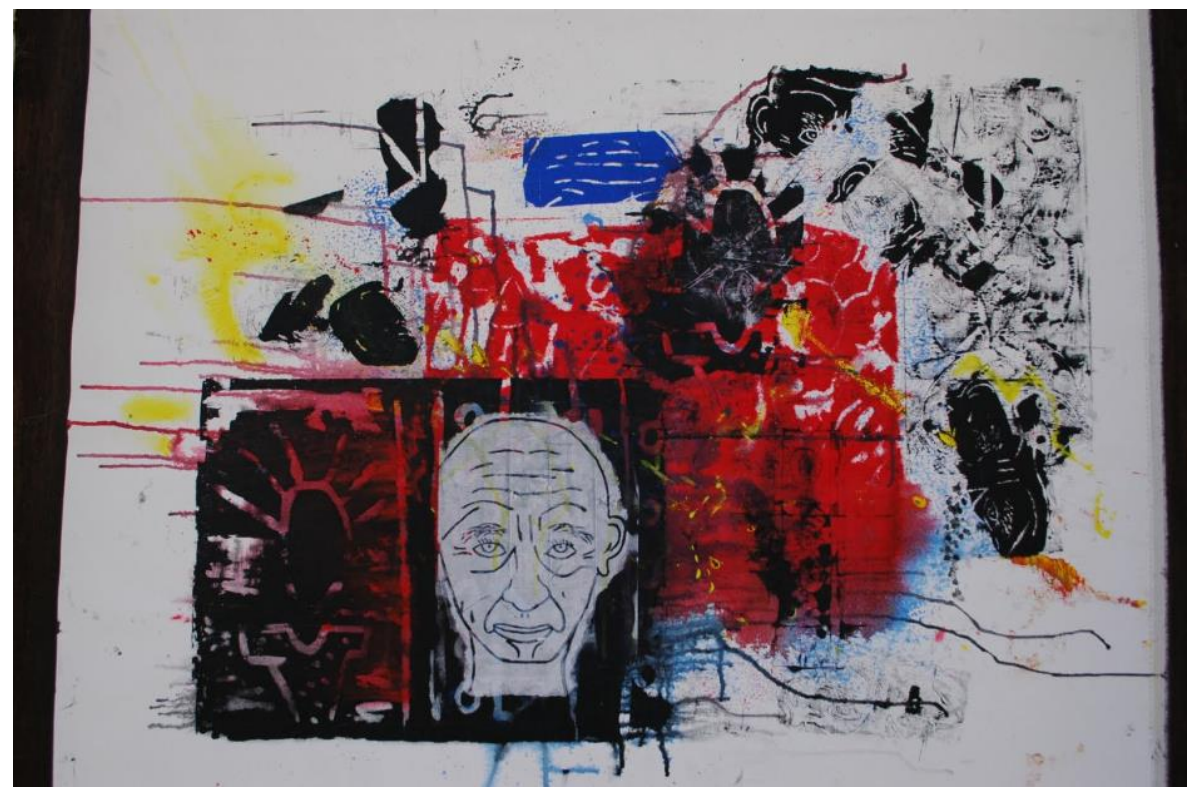

Figura 1 - Deixa meu cabelo em paz ${ }^{5}$

A obra intitulada "Deixa meu cabelo em paz" é autodenominada pelo artista como uma "pintogravura", referência à junção das técnicas de gravura e de pintura. Tal obra parece enquadrar-se na arte contemporânea de ruptura e de modernização, pois alia técnicas da assim chamada "arte urbana" 6 (gravura), mesmo estando alocada em um espaço que não o da arte urbana, as ruas, com pinturas subjetivas. Aqui, entende-se arte urbana como a arte pensada e criada para estar nas ruas, não em museus, ou espaços fechados,

\footnotetext{
${ }^{5}$ Disponível em: <http://linodamiao.blogspot.com.br/>. Acesso em: 13 jul. 2013.

6 "A arte urbana é uma prática social. Suas obras permitem a apreensão de relações e modos diferenciais de apropriação do espaço urbano, envolvendo em seus propósitos estéticos o trato com significados sociais que as rodeiam, seus modos de tematização cultural e política." (PALLAMIN, 2000, p. 23-24).
} 
como manifestação cultural e social de denúncia, representada esteticamente por elementos como a gravura, o graffiti, a stencil art, a sticker, entre outros.

Observa-se na tela em questão o contraste entre uma figura representativa de um indivíduo negro exibindo os seus cabelos e uma figura representativa de um indivíduo branco exibindo a sua calvície. Aliando o verbal (título) e o não verbal (pintogravura) o artista, por meio da representação traz consigo o apelo ao conceito, isto é, a temática como via de significação é desvendada quando o sensível da matéria se converte em significação, como se a obra fosse sua própria temática.

Do contraste entre a figura humana representada pela cor preta e a figura humana representada pela cor branca surge uma dialética de historização de Angola, na referencialização ao processo de colonização portuguesa (brancos) e à luta por independência (negros).

Também, há entre as duas figuras humanas (negra e branca) signos de falta (a calvície do branco) e signos de abundância (o cabelo do negro), funcionando como uma posição de fragilidade do colonizador e de enraizamento cultural do colonizado. $O$ artista parece representar o valor positivo da raça negra a partir de um elemento associativo de abundância (os cabelos) num percurso de intimidação ao preconceito contra os afrodescendentes. O cabelo do negro, então, funciona como um símbolo de identidade negra, de luta contra 0 preconceito, de denuncia contra 0 colonizador e de valorização da cultura afro.

Portanto, há uma desconstrução da generalização preconceituosa do termo "cabelo ruim" associada ao cabelo dos afrodescendentes, no seu contraste à falta de cabelo da figura humana branca, na inversão do negro como dominado política, econômica e culturalmente pelo branco:

O cabelo do negro, visto como "ruim", é expressão do racismo e da desigualdade racial que recai sobre esse sujeito. Ver o cabelo do negro como "ruim" e do branco como "bom" expressa um conflito. Por isso, mudar o cabelo pode significar a tentativa do negro de sair do lugar da inferioridade ou a introjeção deste. Pode ainda representar um sentimento de autonomia, expresso nas formas ousadas e criativas de usar o cabelo. ${ }^{7}$

\footnotetext{
7 Disponível em: <http://www.acaoeducativa.org.br/fdh/wpcontent/uploads/2012/10/Corpo-ecabelo-como-s\%C3\%ADmbolos-daidentidade-negra.pdf>. Acesso em: 14 jul. 2013.
} 
Para que o espectador passe de uma significação afetiva para uma significação intelectiva, em "Deixa meu cabelo em paz”, é necessário, como defende Dufrenne (2001, p. 388) "[...] deixar a aparência, o sentimento primeiro, a imediatez do sensível e buscar a reflexão que mostre a verdade desse objeto".

Logo, parece que o artista, com a utilização de técnicas pictóricas modernas como a gravura, acaba valendo-se de um instrumento associado à cultura urbana, justamente para carregar semiologicamente a sua obra com um sentido de crítica social.

O espectador tem de associar a técnica à temática da obra, na composição do ideário geral interpretativo do todo, já que "os valores da arte contemporânea não são vistos separadamente de problemas da vida urbana e cotidiana" ${ }^{8}$, isto é, ao utilizar a técnica da gravura, Lino Damião perscruta uma identidade de denúncia social na temática de sua obra, já a partir da forma de sua obra.

Interessante notar que, Lino Damião dá continuidade ao conceito de "Negritude", num movimento migratório da Literatura para as Artes plásticas, em "Deixa meu cabelo em paz", na medida em que projeta em sua obra a necessidade de evidenciar os valores reais e simbólicos dos negros, numa atitude de representação de identidade, de defesa do povo negro e de suas características culturais. Conceito perceptível em "Deixa meu cabelo em paz" no que tange à conscientização da característica dos cabelos dos negros como um valor positivo, de afirmação da identidade e de superação da opressão do mundo branco, num sentimento de pertença à "africanidade".

\footnotetext{
${ }^{8}$ Disponível em:<http://www.usp.br/fau/fau/ensino/docentes/deptecnologia/v_pallamin/textos/art e_urbana_critica/arte_urbana_como_pratica_critica.pdf >. Acesso em: 14 jul. 2013.

9"O movimento surgido por volta de 1934, em Paris, e que foi definido pelo poeta antilhano Aimé Césaire como uma revolução na linguagem e na literatura que permitiria reverter 0 sentido pejorativo da palavra negro para dele extrair um sentido positivo, só foi batizado com o nome de negritude em 1939, quando ele é utilizado pela primeira vez em um trecho de Cahier d'um retourn au pays natal (Caderno de um regresso ao país natal), poema de Césaire que se tornou a obra fundamental da negritude; [acrescentando que] a palavra negritude, em francês, tem uma força de expressividade e mesmo de agressividade que se perde em português, por derivar de nègre, termo pejorativo, usado para ofender o negro, uma vez que existe a palavra noir. A idéia foi justamente assumir a denominação negativamente conotada para reverter-lhe 0 sentido, permitindo assim que a partir de então as comunidades negras passassem a ostentálo com orgulho e não mais com vergonha ou revolta." (BERND, 1988, p. 17).
} 
O "assumir-se como negro" é visível na obra de Lino Damião, tanto na representação não verbal, assumida pela positivação do cabelo dos negros como identidade coletiva, bem como na verbalização do título da obra. "Deixa meu cabelo em paz" é ao mesmo tempo a afirmação identitária de um indivíduo negro como a afirmação de seus laços com uma história, cultura e sociedade africana negra:

Buscar o desafio cultural do mundo negro (a identidade negra africana), protestar contra a ordem colonial, lutar pela emancipação de seus povos oprimidos e lançar o apelo de uma revisão das relações entre os povos para que se chegasse a uma civilização não universal como extensão de uma regional imposta pela força - mas uma civilização do universal, encontro de todas as outras, concretas e particulares. (MUNUNGA, 1986, p. 43-44)

Na obra "Na quitanda de munpeque" (pintura sobre tela) o artista explora a figura das "mamãs" quitandeiras a vender o óleo de munpeque ou mompeque, numa referência ao comércio de subsistência existente nos centros urbanos de Angola, e de uma maneira geral, em todos os países africanos.

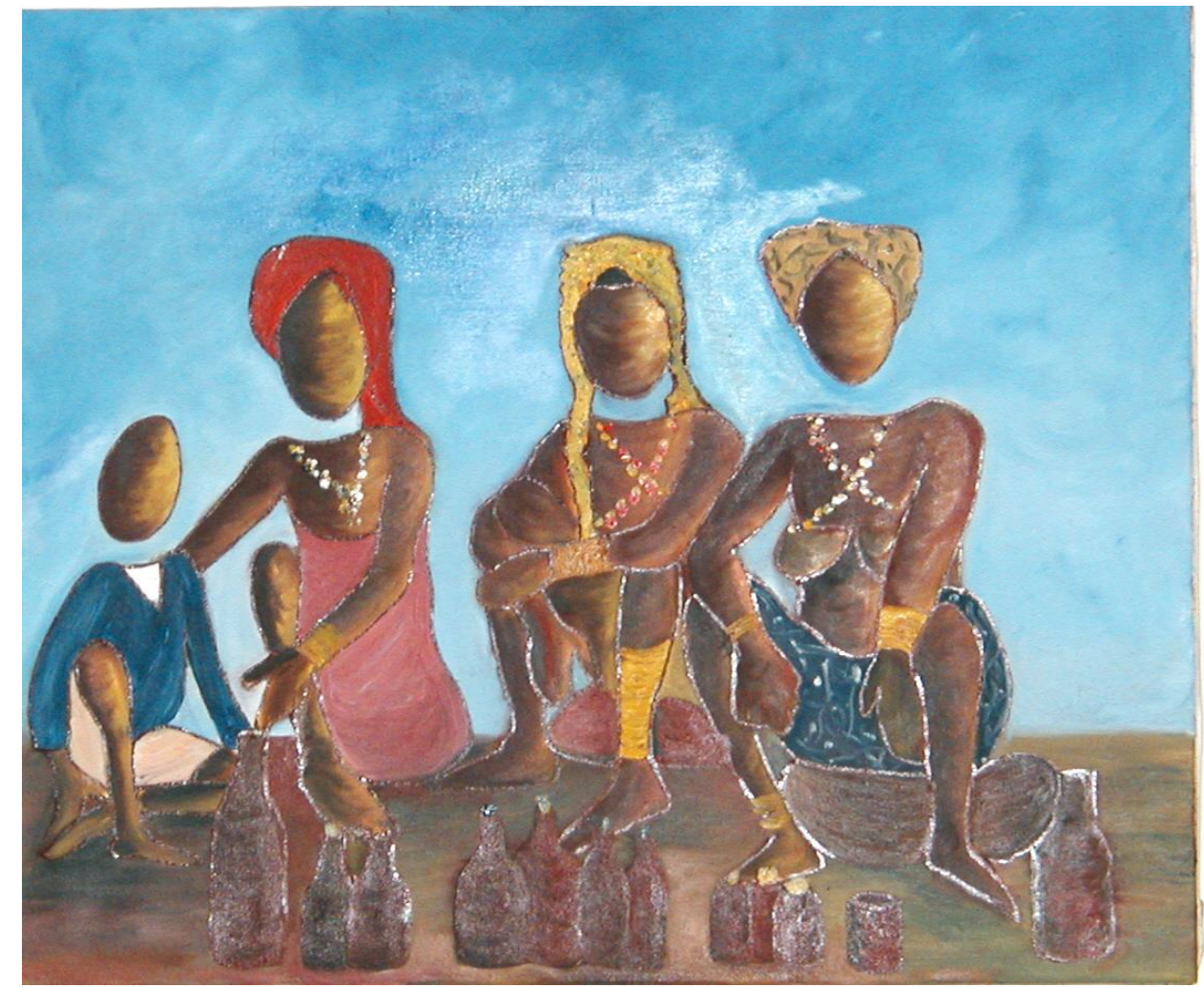

Figura 2 - Na quitanda de munpeque ${ }^{10}$

O artista, por meio da pintura geométrica, estabelece uma reduplicação do cotidiano de centros urbanos de Angola. Por meio de um princípio de

\footnotetext{
${ }^{10}$ Disponível em: <http://linodamiao.blogspot.com.br/search/label/Pintura\%20sobre\%20Tela>. Acesso em: 14 jul 2013.
} 
imitação do real, projeta na sua obra a imagem de três mulheres negras sentadas, cujos corpos, principalmente a cabeça, são construídos geometricamente. Tais mulheres negras estão acompanhadas da imagem de um menino, o qual é alçado pelo iniciar de um abraço (por conta do enlaçamento dos braços) de uma dessas imagens femininas.

Lino Damião parece simbolizar, além da referencialidade a um contexto social e cultural urbano específico de certos países africanos, a citar, o comércio de sobrevivência na remissão aos grandes mercados em espaços abertos, zonas de comercialização informal de produtos; na figura das "mamãs" "buscando em um comércio precário, a luta para combater a própria fome, ao mesmo tempo que, ironicamente, colaboram para saciar a fome alheia" (ALÓS, 2012, p. 125), apresenta uma estética de ancestralidade das origens africanas.

O fato das imagens femininas não apresentarem um rosto definido e individualizado destaca, metonimicamente, a totalização homogeneizante para uma significação simbologizada, isto é, as três imagens femininas da pintura, descaracterizadas nas especificidades individuais de seus rostos vislumbram a imagem de uma feminilidade telúrica, como símbolo da fecundidade e da fidelidade às origens, numa evidente menção ao arquétipo da Mãe-África:

A ideia de uma África configurada como mãe e terra foi um resgate promovido pelo Pan-africanismo, no final do século XIX e início do século $X X$, das tradições culturais pré-coloniais africanas, em um momento histórico em que o negro voltava-se para a descoberta de sua origem. Esse resgate promovido pelo Pan-africanismo foi consolidado pelos movimentos culturais a que ele deu origem (Renascimento Negro norte-americano, Indigenismo haitiano, Negrismo cubano e Negritude francófona), transformando a Mãe-África em uma das principais recorrências temáticas presentes nas literaturas africanas e afro-americanas. (SANTOS, 2012, p. 68)

Cabe ressaltar que a representação da Mãe-África em "Na quitanda de munpeque" é expressa através da concretude de mulheres "reais" do cotidiano africano, "ao contrário do imaginário europeu, que vê o arquétipo da Mãe-África de maneira abstrata e despersonalizada, por vezes quase que simplesmente conceitual" (ALÓS, 2012, p. 125).

Utilizando imagens de mulheres concretas, como a das "mamãs" a vender óleo de munpeque, ou mompeque, o artista revaloriza a significação da Mãe-África na sua projeção menos subjetiva e mais materializada no cotidiano, 
criando um movimento de fusão entre a Grande Mãe Progenitora e a redescoberta da negritude na sociedade, na cultura e na arte.

Ao louvar e exaltar a Mãe-África por meio da sua alusão pictórica em imagens femininas do cotidiano (mulheres concretas), Lino Damião, através de um processo metonímico e metafórico, representa toda a raça, todo o território e as culturas de um continente, isto é, o artista vê na mulher africana nativa a simbologia do mito que engloba, sequencialmente, a mulher, a mãe, a nação e o continente africano, num contato não apenas psicológico e subjetivo, mas que parte da realidade urbana de figuras femininas concretas.

Parece que o artista pretende traduzir em e com sua obra os conceitos de nação e de identidade nacional como identificações simbólicas, construídas discursivamente, com as quais os sujeitos se identificam concretamente. Então, a reconstrução do passado e da ancestralidade matrial através da pintura em questão funciona como um elemento de valorização da cultura negra africana no compartilhamento de uma mesma origem para o resgate dos valores culturais africanos, para a correção das distorções históricas em relação ao negro e para orgulho da negritude:

A nação é uma alma, um princípio espiritual. Constituem essa alma, esse princípio espiritual, duas coisas que, para dizer a verdade, são uma só. Uma delas é a "posse em comum de um rico legado de lembranças"; a outra, o consentimento atual, o desejo de viver juntos, a vontade de continuar a fazer valer a herança que recebemos indivisa. [...] A nação, como o indivíduo, é o resultado de um longo passado de esforços, de sacrifício e de devoções. O culto dos ancestrais é, entre todos, o mais legítimo; os ancestrais fizeram de nós o que somos. "Um passado heróico, grandes homens, glória (refiro-me à verdadeira)", eis o capital social sobre o qual assenta-se uma ideia nacional. Ter glórias comuns no passado, uma vontade comum no presente; ter feito grandes coisas juntos, querer continuar a fazê-las, eis as condições essenciais para ser um povo. (RENAN, 1997, p. 39)

Lino Damião, artista contemporâneo dos séculos XX e XXI acaba mobilizando em suas obras, a declarar, especificamente, em "Deixa meu cabelo em paz" e em "Na quitanda de munpeque", não somente aspectos do cotidiano urbano de certos países africanos, não somente um discurso sobre 0 negro, mas um arquitetar simbólico de uma estética produzida por um sujeito social negro em consonância com as necessidades de denúncia na arte, de realidades sociais observáveis, na luta contra a assimilação da cultura do 
colonizador e na proposta de definição de uma identidade nacional ainda em construção.

A saber, em 2013, duas das últimas grandes possessões africanas de Portugal que se transformaram em países, Moçambique e Angola, celebraram apenas trinta e oito anos de independência política, ou seja, países com um projeto de recuperação de suas identidades específicas, sucumbidas pela violência colonizadora.

Denuncia e resiste às opressões, insere o negro como personagem ligado a uma tradição e a uma origem ancestral comum, e, portanto, não arbitrariamente, utiliza as artes plásticas com o fito de afirmar-se como um promulgador da cultura africana negra, como um artista negro engajado em uma proposta histórica, política, social e cultural de consciência e de comprometimento, na redescoberta de si mesmo, de suas raízes, de referendar identidades nacionais, num pareamento de relações com a poética da negritude:

Os africanos que conseguem estudar e atingir um certo nível de consciência social, mesmo beneficiando de algumas benesses da cidade de betão, tem tendência a sentir-se identificados com a massa da população que vegeta e sobrevive por entre inúmeras dificuldades. A raça, o grupo étnico, cor da pele, funcionam como um sinal de alarme do que eles, nas mesmas condições poderiam ter sofrido na carne. Escrevendo por catarse e revolta, irão descobrir a África profunda, que é como quem diz, a raça e a etnia como factores de cultura, identidade e afirmação. O tema étnico, nesse renascimento, representa para os africanos a busca mirífica de consistência das raízes, da origem, de um específico tronco da árvore da vida. (LARANJEIRA, 1995, p. 414)

Legitimar a voz dos africanos, dentro de um denominador comum, reivindicando a valorização do povo negro de África, através de produções simbólico-culturais, como a literatura e como as artes plásticas (o corpus desse artigo) permite colocar a arte como um trânsito de documentação da história e da cultura dos povos africanos, não somente como um inventário da vida africana, mas também e, sobretudo, como forma de resistência a um sistema de hierarquização do poder, no que concerne ao mundo eurocêntrico.

É com um diálogo com a realidade externa que Lino Damião resgata artisticamente a historicidade, a tradição e as origens do povo negro africano, nos seus costumes e nas suas transversalidades culturais, no desejo de construção de identidades nacionais para os países africanos, denunciando e 
criticando a política colonizadora. Parece ser este o manifesto artístico, ou a tônica artística de Lino Damião:

Urgia, pois, restabelecer o espaço africano, preencher os vazios provocados pela desterritorialização, voltando-se para o local, para o cotidiano, na busca da reconstrução da sua singularidade, daquele traço "uno" que, sobrepondo-se às divergências locais internas, assinalaria, no concerto das nações, a sua diversidade. (DANTAS, 2003, p.42)

\section{REFERÊNCIAS BIBLIOGRÁFICAS}

ALÓS, Anselmo Peres. Versos pós-colonias: manifestações poéticas em São Tomé e Príncipe. In: Itinerários, Araraquara, n. 35, p. 119-130, jul/dez. 2012.

BERND, Zilá. O que é Negritude? São Paulo: Brasiliense, 1988, p. 17.

DUFRENNE, Mikel. Fenomenologia e experiência estética. São Paulo: Perspectiva, 2001.

DANTAS, Elisalva Madruga. Literatura, território e questões sobre hibridismo. In: Literaturas em movimento: hibridismo cultural e exercício crítico, Rita Chaves e Tania Macêdo (org). São Paulo: Arte e Ciência, 2003.

LARANJEIRA, Pires. A Negritude africana de língua portuguesa. Porto: Afrontamento, 1995.

MOURÃO, Fernando Augusto Albuquerque. A sociedade angolana através da literatura. São Paulo: Ática, 1978.

MUNANGA, Kabengele. Negritude: usos e sentidos. São Paulo: Ática, 1986.

PALLAMIN, Vera. Arte urbana. São Paulo: Fapesp, 2000.

RENAN, Ernest. O que é uma nação? In: ROUANET, Maria Helena. Nacionalidade em questão. Rio de Janeiro: UERJ, 1997.

SANTOS, Donizeth. Representações da Mãe-África nas poesias moçambicana e afro-brasileira. In: Abril, Revista do Núcleo de Estudos de Literatura Portuguesa e Africana da UFF, vol. 5, n. 9, p. 67-78, nov. 2012. 